\title{
Aortic arch geometry after the Norwood procedure: The value of arch angle augmentation
}

\author{
Tomomi Hasegawa, MD, PhD, Yoshihiro Oshima, MD, PhD, Ayako Maruo, MD, PhD, \\ Hironori Matsuhisa, MD, PhD, Akiko Tanaka, MD, PhD, Rei Noda, MD, and Shunsuke Matsushima, MD
}

\begin{abstract}
Objective: Aortic arch reconstruction in the Norwood procedure is occasionally associated with postoperative airway and branch pulmonary artery stenosis, as well as recoarctation. This study investigated geometric changes in the aortic arch after the Norwood procedure and evaluated the efficacy of arch angle augmentation with glutaraldehyde-treated autologous pericardium in aortic arch reconstruction.
\end{abstract}

Methods: Of 52 consecutive patients who underwent the Norwood procedure between 1998 and 2013, a total of 36 patients who underwent postoperative multidetector-row computed tomographic angiography were reviewed retrospectively, and divided into 2 groups according to whether arch angle augmentation with glutaraldehyde-treated autologous pericardium was performed (AAA group, 26 patients) or not (NA group, 10 patients).

Results: The neoaortic arch in the Norwood procedure was characterized by having a significantly smaller angle, being lower in height, and being narrower than that in age-matched control patients with a normal aortic arch. Moreover, all of these arch geometric measurements were significantly larger in the AAA group than in the NA group. Freedom from reintervention and reoperation for bronchomalacia or branch pulmonary artery stenosis, caused by extrinsic compression of the neoaorta, was significantly better at 1 year in the AAA group than in the NA group. Recoarctation of the neoaorta was documented in only $1(3.8 \%)$ patient in the AAA group versus 3 patients $(30 \%)$ in the NA group.

Conclusions: Arch angle augmentation with glutaraldehyde-treated autologous pericardium in the Norwood procedure creates more aortopulmonary space with a smoother arch angle and diminished incidence of postoperative recoarctation, bronchial compression, or branch pulmonary artery compression. (J Thorac Cardiovasc Surg 2015;150:358-66)

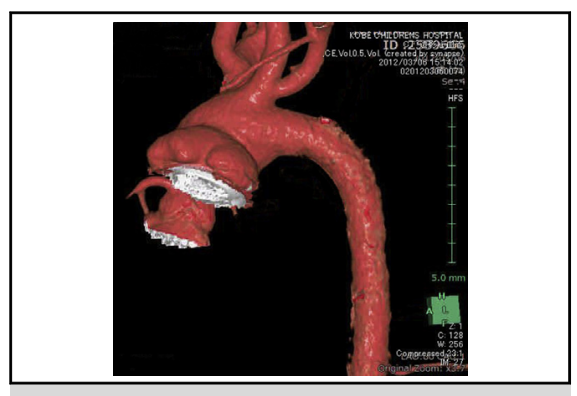

Three-dimensional MDCTA image in a patient who underwent Norwood procedure with arch angle augmentation

Central Message
Aortic arch geometry after the Norwood proce-
dure provides us important anatomical features
that would be related to postoperative
morbidity.
Perspective
Imaging approach using MDCTA is useful for
full assessment of aortic arch geometry. Aortic
arch reconstruction in Norwood procedure is
associated with a smaller angle, lower height,
and narrower width of the neoartic arch. Our
technique of arch angle augmentation creates
more aortopulmonary space with a smoother
arch angle, and prevents postoperative compli-
cations related to neoaortic compression.

See Editorial Commentary page 367.
Although recent improvements in prenatal diagnosis, surgical techniques, and perioperative management have led to a $7 \%$ to $9 \%$ decline in mortality ${ }^{1}$ in patients with hypoplastic

From the Department of Cardiovascular Surgery, Kobe Children's Hospital, Kobe, Japan.

This study received no specific grant from any funding agency in the public, commercial, or not-for-profit sectors.

Received for publication Sept 26, 2014; revisions received Feb 1, 2015; accepted for publication May 3, 2015; available ahead of print June 17, 2015.

Address for reprints: Tomomi Hasegawa, MD, PhD, Department of Cardiovascular Surgery, Kobe Children's Hospital, 1-1-1 Takakuradai, Suma-ku, Kobe 654-0081, Japan (E-mail: tohasegawa_kch@hp.pref.hyogo.jp).

0022-5223/\$36.00

Copyright (c) 2015 by The American Association for Thoracic Surgery

http://dx.doi.org/10.1016/j.jtcvs.2015.05.012 left heart syndrome, the Norwood procedure is still considered technically challenging and high risk, in pediatric cardiac surgery. Since the Norwood procedure was first introduced, ${ }^{2,3}$ in the early 1980s, it has undergone numerous modifications with biological or synthetic materials designed to simplify the operative technique and improve outcomes. Despite these advancements, recoarctation of the reconstructed neoaorta has been recognized as a frequently observed complication after the Norwood procedure and is significantly related to late morbidity and mortality. The documented incidence of the recoarctation ranges ${ }^{4-8}$ from $5 \%$ to $40 \%$.

Although aortic arch reconstruction with complete coarctectomy, and an interdigitating arch anastomosis in the Norwood procedure, diminishes postoperative recoarctation, $5,7,9,10$ 


\section{Abbreviations and Acronyms \\ AAA $=$ arch angle augmentation with GA-AP \\ dAo = descending aorta \\ GA-AP = glutaraldehyde-treated autologous pericardium \\ IAA $=$ interrupted aortic arch \\ MDCTA $=$ multidetector-row computed tomographic angiography \\ NA $=$ no arch angle augmentation \\ $\mathrm{PA} \quad=$ pulmonary artery}

extensive resection of the ductal tissue and coarctation shelf, and tensed anastomosis of a native tissue-to-tissue connection, causes distortion and narrowing of the aortopulmonary space. This deformation has the potential to result in extrinsic compression of the bronchus or branch pulmonary artery (PA) by the neoaorta. The airway compression often leads to long-term ventilator dependency, or recurrent respiratory problems, whereas PA compression leads to high pulmonary vascular resistance, which may impair systemic venous flow and reduce cardiac output.

The success of aortic arch reconstruction in the Norwood procedure involves not only the creation of an adequate and unobstructed pathway for systemic blood flow, but also enlargement of the aortopulmonary space, to avoid postoperative complications related to neoaortic compression. To achieve these goals, we present a technique for aortic arch reconstruction in the Norwood procedure that includes arch angle augmentation with glutaraldehyde-treated autologous pericardium (GA-AP). The aims of the present study were to investigate aortic arch geometry after the Norwood procedure and to evaluate the efficacy of the arch angle augmentation with GAAP in achieving a successful Norwood procedure.

\section{METHODS}

Between October 1998 and July 2013, a total of 52 consecutive patients underwent the Norwood procedure, performed by 1 of 2 surgeons (M.Y. before 2005; Y.O. since 2005) at Kobe Children's Hospital. Of these patients, 36 who had multidetector-row computed tomographic angiography (MDCTA) after surgery were enrolled in the present study. Because the other 16 patients died in the hospital before having the postoperative MDCTA, they were excluded from the present study. Clinical medical records and databases were retrospectively reviewed. This study was performed with the approval of the institutional review board (registration no. R26-12), and the need for individual consent was waived.

\section{Patient Characteristics}

The median age and body weight at the time of the Norwood procedure was 32 days (range: $1-149$ days) and $3.3 \mathrm{~kg}$ (range: $2.3-5.4 \mathrm{~kg}$ ), respectively. Of the 36 patients, 25 were male and 11 were female. The primary diagnoses included hypoplastic left heart syndrome and its anatomic variants in 18 patients, and interrupted aortic arch (IAA)/coractation of the aorta (CoA) complex with left ventricular outflow tract obstruction in 18 patients. Twenty patients $(55.6 \%)$ underwent a modified hybrid procedure consisting of bilateral PA banding at a median age of 5 days (range: 2-60 days) and lipo-prostaglandin $\mathrm{E}_{1}$ infusion, with hospitalization until the time of the Norwood procedure.

\section{Norwood Procedure}

After routine midline sternotomy, cardiopulmonary bypass was established with arterial cannulation of the innominate artery, with or without interposition of a polytetrafluoroethylene graft for upper-body perfusion, and the descending aorta ( $\mathrm{dAo}$ ) for lower-body perfusion. Venous drainage was obtained by bicaval cannulation, and moderate systemic hypothermia, and cold blood cardioplegic arrest was applied. Ductus arteriosus was divided by complete resection of the ductal and coarctation tissues, and the pulmonary trunk was transected at its bifurcation. After the dAo was cut back on the ventral side, the proximal end of the pulmonary trunk was anastomosed side-by-side to the dAo. Since 2005 , GA-AP $(0.6 \%$ for $5 \mathrm{mi}-$ nutes) was interposed between the pulmonary trunk and the dAo in most patients (Figure 1, A). The hypoplastic aortic arch and ascending aorta were opened longitudinally, and the neoaorta was reconstructed by sewing the adjacent walls of those great vessels.

Additional patch augmentation sewn to the anterior wall of the neoaorta was performed to prevent kinking and torsion at its anastomotic site, by using GA-AP in 6 patients in the AAA group, and an equine pericardial patch in 1 patient in the NA group. All the anastomoses were performed with $7-$ 0 Prolene (polypropylene; Ethicon, Inc, Somerville, NJ) sutures in a running fashion. Pulmonary blood flow was provided by a 5- or 6-mm, right ventricle-to-PA shunt, passing to the left of the neoaorta (Figure 1,B). Medium-sized hemostatic clips (Weck Hemoclip Traditional, Teleflex Medical, Research Triangle Park, NC) was placed in the midportion of the shunt for a control of pulmonary blood flow, if necessary. A large interatrial communication was created in all patients.

\section{Study Design}

The aortic arch geometry on MDCTA for the 36 patients (Norwood patients) enrolled in the present study was retrospectively compared with that for the 20 age-matched patients who had normal visceral arrangement and normal aortic arch geometry without airway compression (patients in the control group). The age matching was performed by randomly selecting patients from among those who underwent preoperative MDCTA for congenital heart disease, in our institution, between January 2010 and July 2013. Median and mean ages at the MDCTA in Norwood patients were 3.8 months (range: 1.1-14.3 months) and $4.6 \pm 2.7$ months, respectively, whereas patients in the control group were 3.8 months (range: 1.2-13.6 months) and $4.5 \pm 3.2$ months, respectively.

The Norwood patients were divided into 2 groups according to the surgical procedures used for aortic arch reconstruction: arch angle augmentation with GA-AP (AAA group; $\mathrm{n}=26$ ); and no arch angle augmentation (NA group; $n=10$ ). The perioperative data and outcomes from the 2 groups were compared. Patient demographics are summarized in Table 1.

\section{Study Outcomes}

The primary endpoint was reintervention and reoperation for postoperative bronchomalacia, or branch PA stenosis, which were caused by extrinsic compression of the neoaorta. The bronchomalacia and branch PA stenosis were detected by bronchoscopy and echocardiography, respectively. Evidence of extrinsic compression of the neoaorta was confirmed by pulsatile compression on the bronchial wall, on bronchoscopy, and by neoaortic compression of the bronchus or branch PA, on MDCTA The other primary endpoint was reintervention and reoperation for postoperative recoarctation.

\section{Aortic Arch Geometry}

Geometric analysis of the aortic arch was performed using MDCTA. The images were acquired at 0.25 -mm collimation on a 64 -slice multidetector row scanner (Aquilion Premium; Toshiba Medical Systems, Tochigi, Japan) and were reconstructed at $0.5-\mathrm{mm}$ intervals on a workstation for 3dimensional imaging (Synapse Vincent, version 3.0; Fujifilm Medical Co, Tokyo, Japan). Geometric data for the aortic arch were collected by measuring the following parameters: (1) "arch angle" between the 2 tangent 

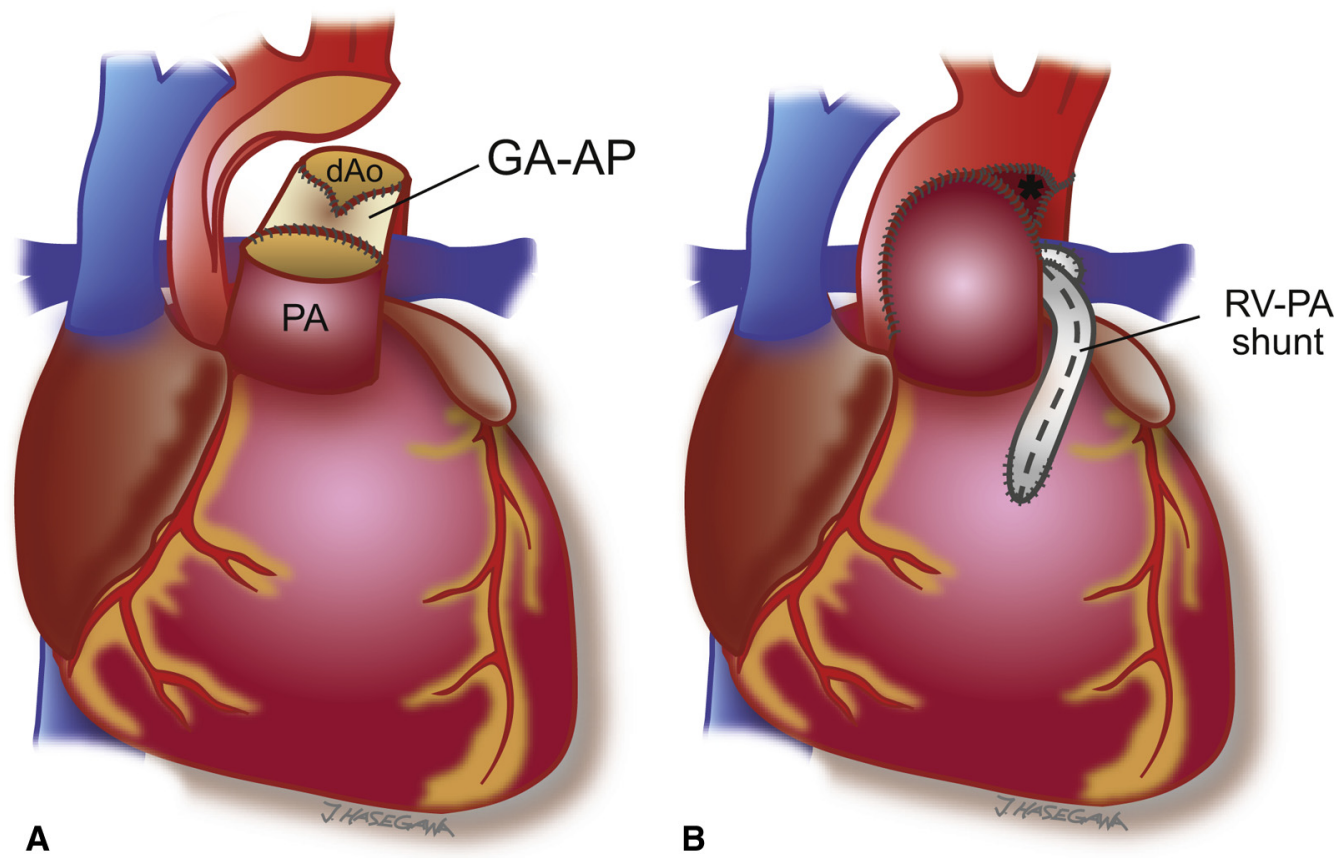

FIGURE 1. Diagram depicting the Norwood procedure. A, Augmentation of the aortic arch with GA-AP. The GA-AP is interposed between the PA and the dAo. B, Aortic arch reconstruction with right-ventricle-to-pulmonary-artery (RV-PA) shunt. Additional patch augmentation (*) for the anterior wall of the neoaorta is performed, if necessary. $d A o$, Descending aorta; $G A-A P$, glutaraldehyde-treated autologous pericardium; $P A$, pulmonary trunk; $R V-P A$, rightventricle-to-pulmonary-artery.

TABLE 1. Demographics of patients who underwent the Norwood procedure

\begin{tabular}{|c|c|c|}
\hline \multirow[b]{2}{*}{ Characteristic } & \multicolumn{2}{|c|}{ Norwood patients } \\
\hline & $\mathbf{A A A}(\mathbf{n}=\mathbf{2 6})$ & NA $(n=10)$ \\
\hline Male/Female & $18 / 8$ & $7 / 3$ \\
\hline Age at surgery (d [range]) & $32(2-149)$ & $28(1-85)$ \\
\hline BW at surgery $(\mathrm{kg})$ & $3.3(2.7-5.4)$ & $3.3(2.3-5.3)$ \\
\hline \multicolumn{3}{|l|}{ Diagnosis } \\
\hline HLHS and its variant & 14 & 4 \\
\hline MS, AS & 6 & 2 \\
\hline MS, AA & 1 & 0 \\
\hline MA, AA & 6 & 2 \\
\hline MA, AS & 1 & 0 \\
\hline IAA/CoA complex with LVOTO & 12 & 6 \\
\hline IAA, type A & 1 & 0 \\
\hline IAA, type B & 4 & 3 \\
\hline $\mathrm{CoA}$ & 7 & 3 \\
\hline Size of ascending aorta (mm) & $5.5(1.3-9.0)$ & $5.3(2.0-14.0)$ \\
\hline Aberrant right subclavian artery & 4 & 3 \\
\hline Bilateral pulmonary artery banding & 16 & 4 \\
\hline Age at postoperative MDCTA (mo) & $3.5(1.3-14.3)$ & $4.7(1.1-9.5)$ \\
\hline $\begin{array}{l}\text { Duration between operation and } \\
\text { postoperative MDCTA (mo) }\end{array}$ & $2.1(0.7-14.1)$ & $4.3(1.1-9.1)$ \\
\hline Follow-up period (y) & $2.6(0.5-8.2)^{*}$ & $6.4(0.4-15.3)$ \\
\hline
\end{tabular}

Data are given as median value (range [minimum - maximum]), or n. $A A A$, Arch angle augmentation; $N A$, no arch angle augmentation; $B W$, body weight; $H L H S$, hypoplastic left heart syndrome; $M S$, mitral stenosis; $A S$, aortic stenosis; $A A$, aortic atresia; $M A$, mitral atresia; IAA, interrupted aortic arch; $C o A$, coarctation of the aorta; LVOTO, left ventricular outflow tract obstruction; MDCTA, multidetector-row computed tomographic angiography. $* P<.05$ versus NA group. lines from the highest point of the aortic arch to the centerline of the aortic arch, on sagittal oblique multiplanar reconstruction images; (2) "arch height" between the inferior margin of the aortic arch and the superior margin of the left main bronchus, on sagittal oblique multiplanar reconstruction images; and (3) "arch width" between the posterior margin of the ascending aorta and the anterior margin of the dAo at the level of the left main bronchus on axial multiplanar reconstruction images (Figure 2). The data for the arch height and the arch width were adjusted for patient height.

In addition, a minimal diameter of the aortic arch was measured at the anastomotic site in patients who underwent the Norwood procedure, or at the isthmus in patients in the control group, and the diameter of the dAo at the level of the diaphragm was measured in both groups of patients. The ratio of aortic arch diameter to dAo diameter ("arch/dAo diameter ratio") was calculated.

\section{Statistical Analysis}

Data are given as mean value with $\mathrm{SD}$, or median value with range, as appropriate. Mean values were compared for normal distributions, using the Student $t$ test, and median values were compared for non-normal distributions with the Mann-Whitney $U$ rank-sum test. The Fisher exact test was used for categoric data. The Kaplan-Meier method was used to estimate the freedom from postoperative bronchomalacia/branch PA stenosis, and recoarctation.

A Cox proportional hazard regression model was used to evaluate the impact of potential risk factors for those postoperative events in univariate and multivariate analyses. Variables included: age; body weight; diagnosis (hypoplastic left heart syndrome and its variants or IAA/CoA complex with left ventricular outflow tract obstruction); ascending aorta size; operative strategy (univentricular or biventricular repair); variability between the 2 surgeons; bilateral PA banding; additional patch augmentation; arch geometric measurements; and study group (AAA or NA). Variables with a $P$ value of $<.1$ in the univariate analysis were included in the multivariate 

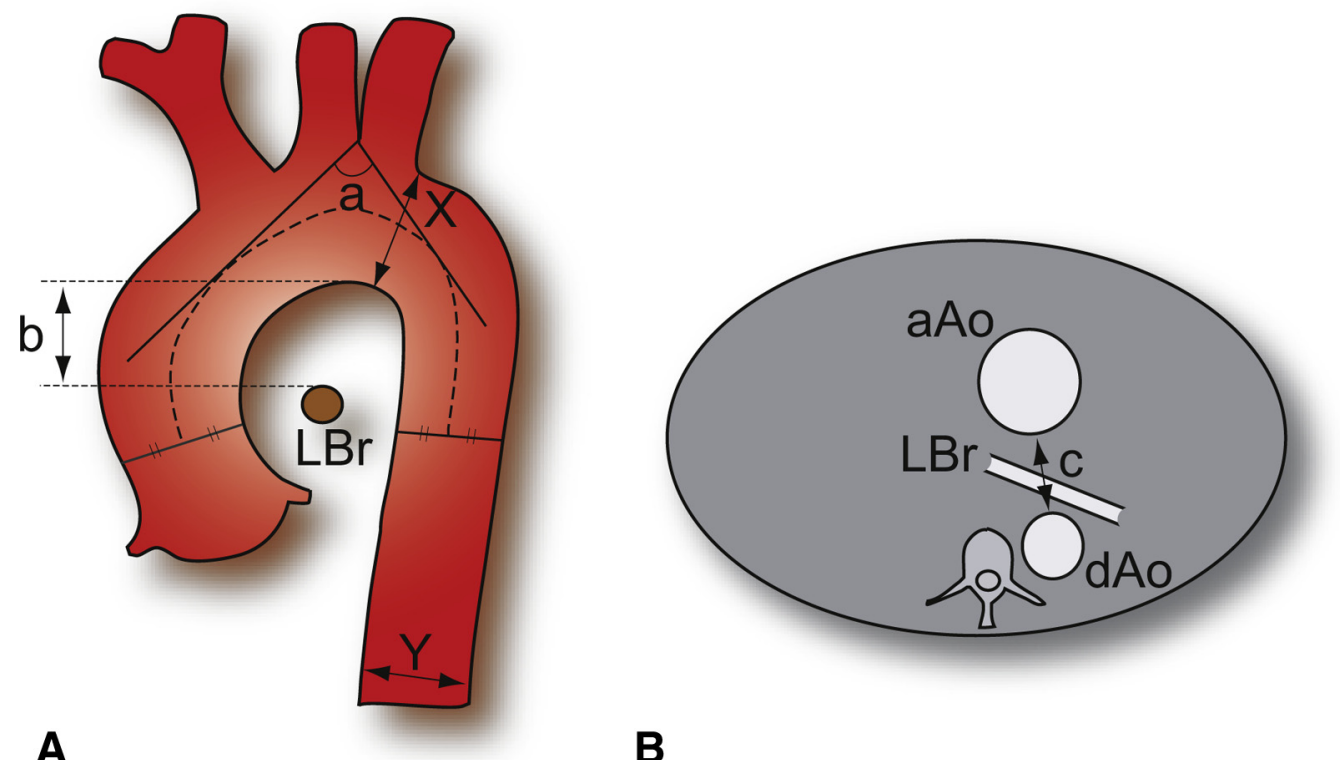

B

FIGURE 2. Measurement of the aortic arch geometry. A, Left lateral oblique computed tomography projection. a = arch angle (angulation between the 2 tangent lines from the highest point of the aortic arch to the centerline of the aortic arch); $b=$ arch height (distance between the inferior margin of the aortic arch and the superior margin of the left main bronchus); $\mathrm{X}=$ minimal diameter of the aortic arch at the anastomotic site in the Norwood group or at the isthmus in the control group; $\mathrm{Y}=$ diameter of the dAo at the level of the diaphragm. The ratio of $\mathrm{X}$ to $\mathrm{Y}$ is calculated as "arch/dAo diameter ratio." B, Axial computed tomography projection. $a A o$, Ascending aorta; $L B r$, left main bronchus; $d A o$, descending aorta.

analysis. Data were analyzed using Stat View J-5.0 software (SAS Institute, Inc, Cary, NC) and GraphPad Prism software 5.0 (GraphPad Software Inc, San Diego, Calif).

\section{RESULTS}

\section{Postoperative Outcomes}

The median follow-up period after the Norwood procedure was 3.3 years (range: 4.3 months to 15.1 years). Of the 36 patients who underwent the Norwood procedure, 13 $(36.1 \%)$ had Fontan completion, 24 (66.7\%) bidirectional Glenn palliation, and $9(25.0 \%)$ the Yasui operation (Figure 3, A). Six late deaths occurred: secondary to severe infection in 3 patients; acute encephalopathy in 1 patient; subdural hemorrhage in 1 patient; and circulatory collapse after cardiac catheterization in 1 patient. Postoperative events for bronchomalacia, branch PA stenosis, or recoarctation occurred in 7 patients in the AAA group (26.9\%), and 7 patients in the NA group $(70.0 \%$ ) (Figure $3, B$ ).

Tracheostomy for bronchomalacia was performed in 3 patients ( 2 in the AAA group, and 1 in the NA group) who required prolonged mechanical ventilation. In the NA group, aortoplasty and aortopexy were performed postoperatively for relief of neoaortic compression of the bronchus in 1 patient each. Branch PA stenosis due to neoaortic compression required balloon angioplasty in 5 patients ( 2 in the AAA group, 3 in the NA group), and reoperation in 6 patients ( 4 in the AAA group, 2 in the NA group). Four of these 6 patients who had reoperation underwent left PA patch plasty (3 in the AAA group, 1 in the NA group); the remaining 2 patients underwent anterior translocation of the right $\mathrm{PA}$ in the Yasui operation.

Freedom from bronchomalacia/branch PA stenosis at 1 year and 5 years in the AAA group was significantly better than for those in the NA group (1 year: 74.6 vs $68.6 \% ; \quad 5$ years: 69.9 vs $23.9 \% ; \quad P=.0361$; Figure 4, A). Reintervention for recoarctation was performed in 1 patient in the AAA group $(3.8 \%)$, with balloon angioplasty; the same reoperation was performed in 3 patients in the NA group $(30.0 \%)$. Freedom from recoarctation at 1 year and 5 years in the AAA group was significantly better than for those in the NA group ( 1 year: 95.8 vs $77.8 \%$; 5 years: 95.8 vs $66.7 \%$; $P=.0246$; Figure $4, B)$.

\section{Aortic Arch Geometry}

Typical 3-dimensional-MDCTA images are shown in Figure 5, and geometric data for the aortic arch on MDCTA are summarized in Tables 2 and 3. The aortic arch in the patients who underwent the Norwood procedure, compared with those in the control group, had a significantly smaller angle (99 \pm 9 vs $108 \pm 6^{\circ}, P=.0005$ ); was lower in height $(29.2 \pm 6.4$ vs $32.3 \pm 3.0 \mathrm{~mm} / \mathrm{m} ; P<.0001)$; and was narrower $(9.7 \pm 3.5 \mathrm{vs} 15.7 \pm 3.0 \mathrm{~mm} / \mathrm{m} ; P=.0458)$. In the patients in the Norwood group, these 3 variables in the AAA group were significantly larger than those in the NA group (arch angle: $103 \pm 6$ vs $88 \pm 6^{\circ} ; P<.0001$; 


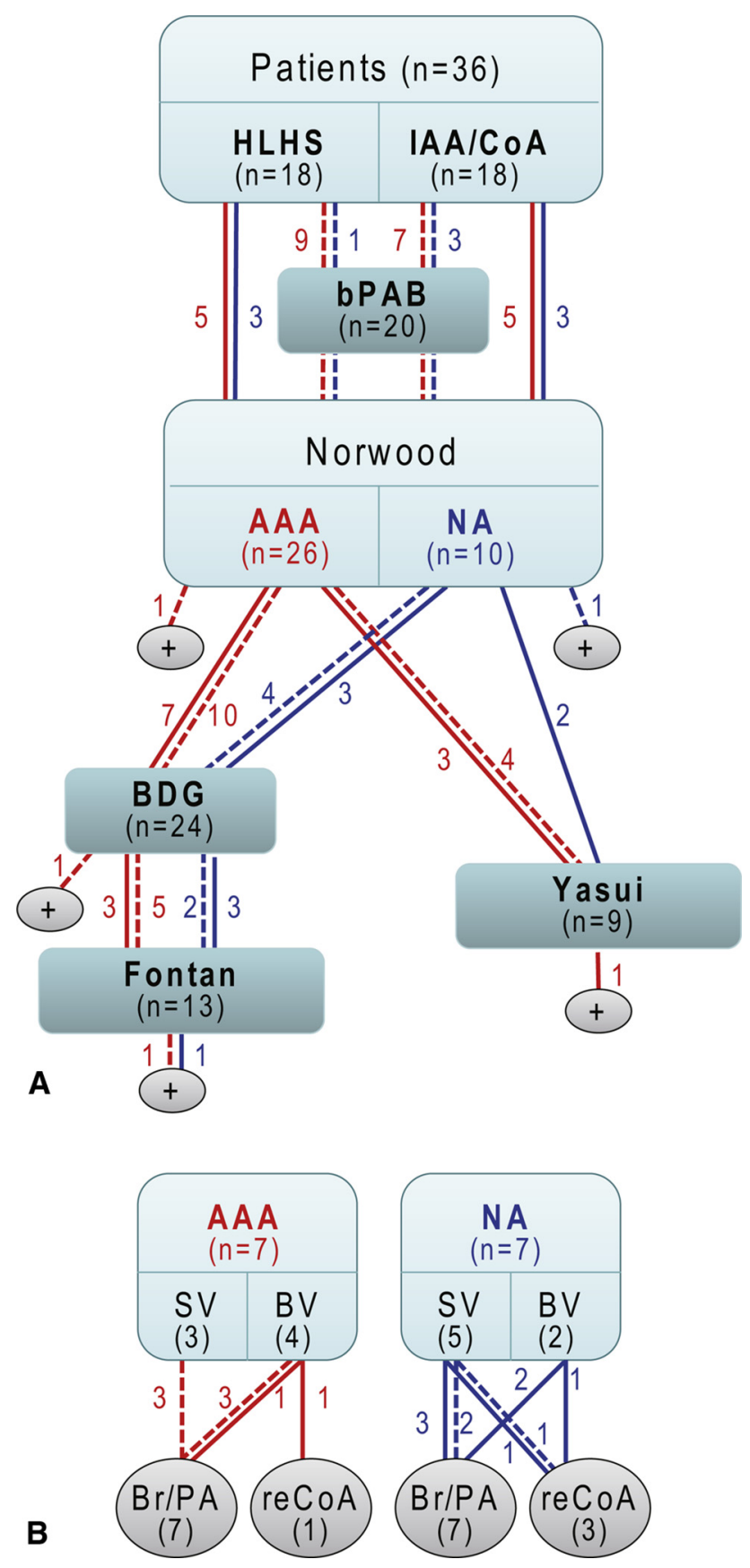

FIGURE 3. Flow diagram that demonstrates (A) the groups and (B) the postoperative events. The solid line shows the flow diagram for patients who did not undergo bPAB. The broken line shows the flow diagram for patients who underwent $\mathrm{BPAB}$. HLHS, Hypoplastic left heart syndrome and its variants; $I A A / C O A$, interrupted aortic arch and coarctation complex with left ventricular outflow tract obstruction; $b P A B$, bilateral pulmonary artery banding; $A A A$, arch angle augmentation group (red); $N A$, no arch angle augmentation group (blue); $B D G$, bidirectional Glenn; $S V$, single-ventricle physiology; $B V$, biventricular physiology; $B r / P A$, reintervention and reoperation for bronchomalacia or branch pulmonary artery stenosis; reCoA, reintervention and reoperation for recoarctation.
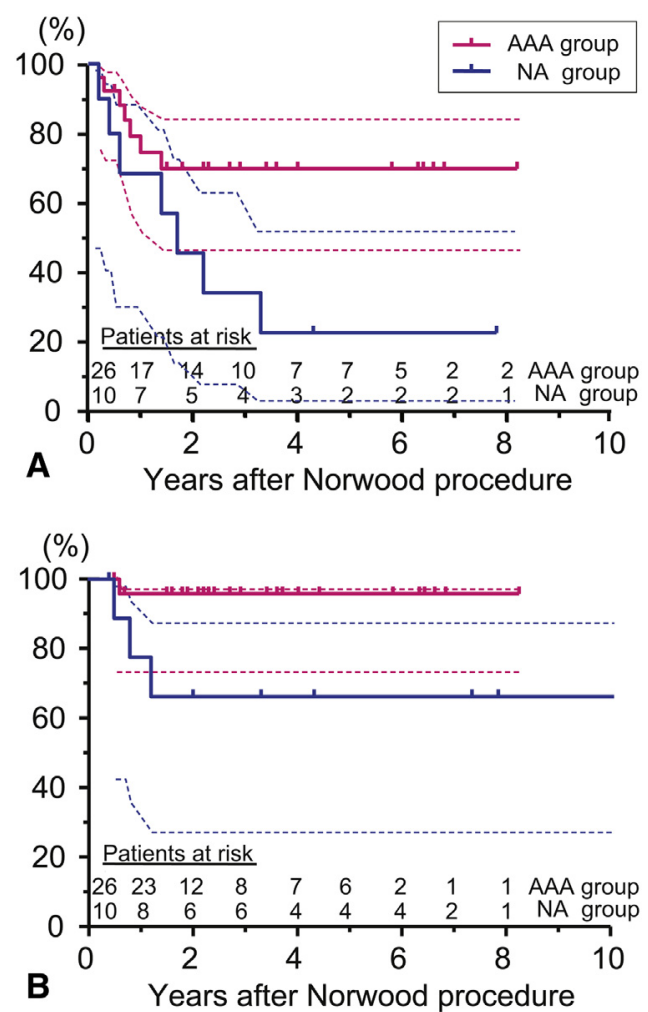

FIGURE 4. Freedom from reintervention/reoperation for (A) bronchomalacia and branch PA stenosis, and (B) recoarctation. AAA, Arch angle augmentation group; $N A$, no arch angle augmentation group. The dotted line represent the $95 \%$ confidence intervals.

arch height: $31.9 \pm 4.7$ vs $21.9 \pm 3.9 \mathrm{~mm} / \mathrm{m} ; P=.0053$; arch width: $10.7 \pm 3.4$ vs $7.2 \pm 2.2 \mathrm{~mm} / \mathrm{m} ; P<.0001)$. The arch/ dAo diameter ratio in the AAA group was significantly larger than that in the NA group $(0.97 \pm 0.06$ vs $0.87 \pm 0.07$; $P=.0002)$.

\section{Univariate and Multivariate Analyses}

Table 4 summarizes univariate and multivariate Cox regression analysis of reintervention and reoperation for bronchomalacia or branch PA stenosis. Arch angle, arch height, arch width, arch/dAo diameter ratio, NA group, and biventricular repair were identified as risk factors on the univariate analysis. Of these variables, the arch width was a significantly independent risk factor on the multivariate analysis. The univariate analysis for recoarctation identified that arch angle $(P=.0145)$ and $\operatorname{arch} / \mathrm{dAo}$ diameter ratio $(P=.0491)$ were significant risk factors. The arch angle was a significantly independent risk factor on the multivariate analysis $(P=.0398)$.

\section{DISCUSSION}

Aortic arch repair in patients with congenital cardiac and aortic arch anomalies is associated with a high probability of 


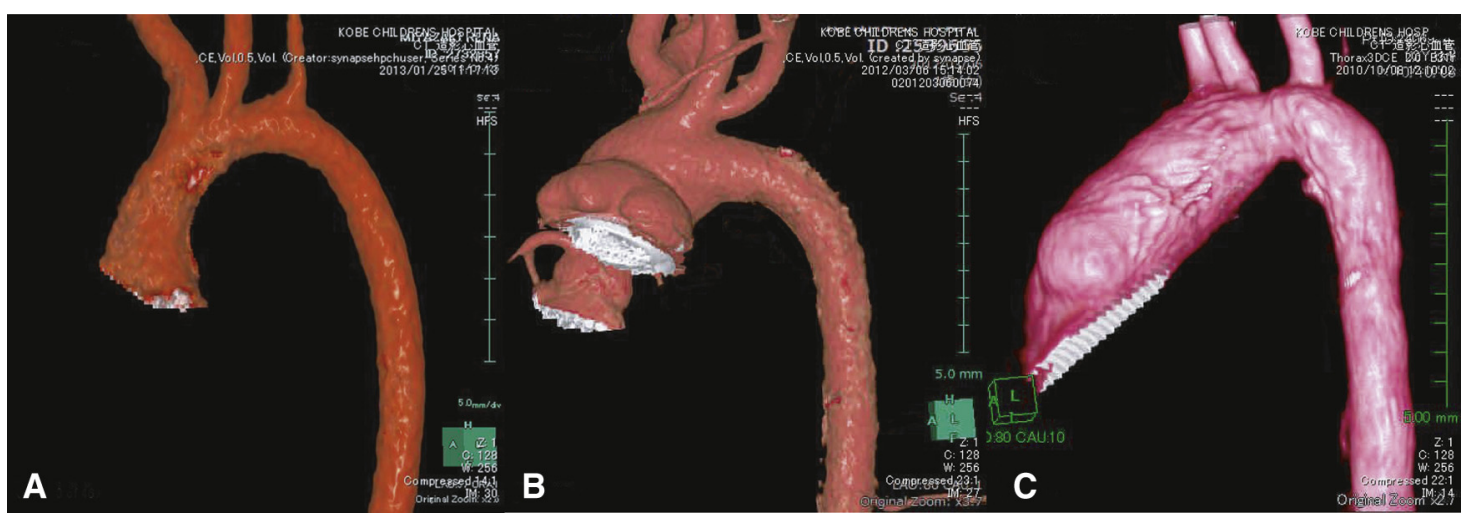

FIGURE 5. Typical 3-dimensional multidetector-row computed tomographic angiography image in each group: (A) control patient; (B) Norwood patient, arch angle augmentation; and (C) Norwood patient, no arch angle augmentation.

changes in the arch geometry, such as the size, shape, and position, resulting in deformation of the anatomic configuration of adjacent tissues. Although previous studies have investigated geometric changes after surgery for CoA/IAA and transposition of the great arteries, ${ }^{11-16}$ aortic arch geometry after the Norwood procedure has rarely been studied. The initial finding of this study is that the aortic arch geometry after the Norwood procedure is characterized by a neoaortic arch that has a smaller angle, is lower in height, and is narrower. This finding has been empirically recognized as common knowledge in the field of pediatric cardiac surgery, but this study is the first to demonstrate geometric changes in the neoaorta after the Norwood procedure, compared with a normal aortic arch, as shown on MDCTA.

In the United States and Europe, the preferred approach to aortic arch reconstruction in the Norwood procedure has been use of a homograft patch for augmentation and geometric preservation of the neoaorta by a simple technique ${ }^{5,7,8}$; in Japan, the homograft is not covered by the national health insurance, and its supply is extremely limited. Some type of patch material is necessary to make up for a shortage in homograft material available for aortic arch reconstruction, but exogenous patch materials often introduce risk for recoarctation, owing to calcification and the immune response. Recently, some surgeons in the United States and Europe have begun to avoid using homografts in the

TABLE 2. Aortic arch geometry on multidetector-row computed tomographic angiography: patients who underwent Norwood procedure versus patients in control group

\begin{tabular}{lcc}
\hline \multicolumn{1}{c}{ Variables } & $\begin{array}{c}\text { Norwood patients } \\
(\mathbf{n}=\mathbf{3 6})\end{array}$ & $\begin{array}{c}\text { Control patients } \\
(\mathbf{n}=\mathbf{2 0})\end{array}$ \\
\hline Arch angle $\left({ }^{\circ}\right)$ & $99 \pm 9^{*}$ & $108 \pm 6$ \\
Arch height $(\mathrm{mm} / \mathrm{m})$ & $29.2 \pm 6.4^{*}$ & $32.3 \pm 3.0$ \\
Arch width $(\mathrm{mm} / \mathrm{m})$ & $9.7 \pm 3.5^{*}$ & $15.7 \pm 3.0$ \\
Arch/dAo diameter ratio & $0.94 \pm 0.07$ & $0.94 \pm 0.06$ \\
\hline
\end{tabular}

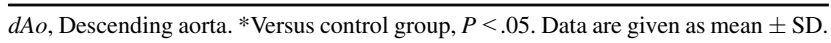

Norwood procedure, given the cost and alloimmunization required.

Aortic arch reconstruction using autologous great vessel tissue only was first described by Fraser and Mee, ${ }^{17}$ and their group ${ }^{10}$ had shown previously that this technique without the use of patch augmentation had a low incidence of recoarctation. However, recent studies demonstrated that the limited availability of native tissues in hypoplastic aortic arch causes tensed anastomosis of the neoaortic arch, easily resulting in distortion and narrowing of the neoaorta. ${ }^{5,18}$ In our institution, the technique of direct anastomosis between the proximal PA trunk and the dAo was initially performed without patch material, and gradually shifted to use of GAAP for arch angle augmentation since 2005.

Recoarctation of the neoaorta is a well recognized complication after the Norwood procedure, and it is a significant cause of morbidity and mortality. However, 2 recent papers, by Burkhart and colleagues ${ }^{5}$ and Lamers and colleagues, ${ }^{7}$ described the interdigitating arch reconstruction using a homograft patch with respective rates of recoarctation of $0 \%(n=0$ of 33$)$ and $2 \%(n=1$ of 63$)$. Although our technique for aortic arch reconstruction used a GA-AP patch, rather than a homograft, the $3.8 \%$ incidence of recoarctation ( $\mathrm{n}=1$ of 26$)$ seems to be excellent.

The patients in the group who underwent AAA had a sufficient arch/dAo diameter ratio, and a low pressure gradient between the ascending aorta and the dAo, of $0.92 \pm 1.28$

TABLE 3. Aortic arch geometry on multidetector-row computed tomographic angiography in the Norwood procedure: aortic arch augmentation versus no aortic arch augmentation

\begin{tabular}{lcc}
\hline & \multicolumn{2}{c}{ Norwood patients } \\
\cline { 2 - 3 } \multicolumn{1}{c}{ Variables } & AAA group $(\mathbf{n}=\mathbf{2 6})$ & NA group $(\mathbf{n}=\mathbf{1 0})$ \\
\hline Arch angle $\left(^{\circ}\right)$ & $103 \pm 6^{*}$ & $88 \pm 6$ \\
Arch height $(\mathrm{mm} / \mathrm{m})$ & $31.9 \pm 4.7^{*}$ & $21.9 \pm 3.9$ \\
Arch width $(\mathrm{mm} / \mathrm{m})$ & $10.7 \pm 3.4^{*}$ & $7.2 \pm 2.2$ \\
Arch/dAo diameter ratio & $0.97 \pm 0.06^{*}$ & $0.87 \pm 0.07$ \\
\hline Da
\end{tabular}

Data are given as mean value \pm SD. $A A A$, Arch angle augmentation; $N A$, no arch angle augmentation; $d A o$, descending aorta. *Versus NA group, $P<.05$. 
TABLE 4. Cox proportional hazard regression analysis of reintervention/reoperation for bronchomalacia or branch pulmonary artery stenosis

\begin{tabular}{|c|c|c|c|c|c|c|}
\hline \multirow[b]{2}{*}{ Variables } & \multicolumn{3}{|c|}{ Univariate } & \multicolumn{3}{|c|}{ Multivariate } \\
\hline & HR & $95 \%$ CI & $P$ value & HR & $95 \%$ CI & $P$ value \\
\hline Age & 1.00 & $0.99-1.02$ & .1496 & & & \\
\hline Body weight & 1.56 & $0.85-2.89$ & .1540 & & & \\
\hline Diagnosis (HLHS and its variants) & 1.03 & $0.36-2.94$ & .9589 & & & \\
\hline Size of ascending aorta & 1.20 & $0.93-1.55$ & .1612 & & & \\
\hline Operative strategy (BVR) & 0.34 & $0.12-0.99$ & .0477 & 0.35 & $0.08-1.52$ & .1619 \\
\hline Surgeon (Y.O.) & 2.05 & $0.57-7.36$ & .2715 & & & \\
\hline Bilateral PA banding & 0.80 & $0.28-2.33$ & 6879 & & & \\
\hline Additional patch augmentaion & 1.00 & $0.28-3.58$ & .9952 & & & \\
\hline Arch angle & 0.94 & 0.89-0.99 & .0317 & 0.99 & 0.90-1.09 & .8243 \\
\hline Arch height & 0.84 & $0.69-1.03$ & .0897 & 0.95 & $0.77-1.16$ & .5839 \\
\hline Arch width & 0.89 & $0.82-0.96$ & .0024 & 0.83 & $0.70-0.99$ & .0356 \\
\hline Arch/dAo diameter ratio & 0.01 & $0.00-0.18$ & .0159 & 0.01 & $0.00-1.95$ & .0631 \\
\hline NA group & 0.23 & $0.10-0.80$ & .0176 & 4.81 & $0.18-130$ & .3516 \\
\hline
\end{tabular}

$H R$, Hazard ratio; $C I$, confidence interval; $H L H S$, hypoplastic left heart syndrome; $B V R$, biventricular repair; $P A$, pulmonary artery; $d A o$, descending aorta; $N A$, no arch angle augmentation.

$\mathrm{mm} \mathrm{Hg}$ on postoperative cardiac catheterization. Only 1 patient in that group, who had IAA type B, ventricular septal defect, and aortic atresia with an extremely diminutive aortic arch, experienced postoperative recoarctation, with a pressure gradient of $22 \mathrm{~mm} \mathrm{Hg}$, and underwent balloon angioplasty twice. Interrupted aortic arch type B is 1 of the incremental risk factors for recurrent arch obstruction. ${ }^{19}$ Because the interrupted gap between the left common carotid artery and left subclavian artery carries the risk of recoarctation or bronchial compression in the aortic arch reconstruction, we recently performed adequate patch augmentation to replenish the anterior wall of the neoaorta using GA-AP or a PA autograft patch in patients with IAA type $\mathrm{B}^{20}$

Human autologous pericardium is a biological tissue widely used as a biomaterial in the field of pediatric cardiac surgery, and it presents several advantages, such as easy availability and handling and the avoidance of donorderived pathogens and an immune response. ${ }^{21}$ Stabilization of the pericardium is often performed with a solution of $0.2 \%$ to $0.625 \%$ glutaraldehyde, to prevent secondary shrinkage and aneurysmal formation, ${ }^{22,23}$ and recommendations for the duration of its stabilization have varied from 10 to 60 minutes. ${ }^{22}$ However, a long fixation with glutaraldehyde would lead to local cytotoxicity, persistent inflammation, calcification, and necrosis at the site of application. Recently, Bernabei and colleagues ${ }^{24}$ showed that the use of GA-AP ( $0.6 \%$ for 5 minutes) is effective for aortic arch reconstruction in the Norwood procedure. Harvested autologous pericardium has been treated with $0.6 \%$ glutaraldehyde solution for 5 minutes in this series, but further follow-up of the neoaortic arch morphology is needed.

Currently, the preferred surgical procedure for aortic arch reconstruction in the Norwood procedure at our institution consists of patch augmentation of the inner curvature of the neoaorta with GA-AP, after complete ductal excision, and cutback on the ventral side of the dAo. At the beginning of our experience, the dimensions of GA-AP were a width of 7 to $10 \mathrm{~mm}$, and a length of $10 \mathrm{~mm}$. Recently, the GAAP used was slightly enlarged, with a width of 10 to 15 $\mathrm{mm}$, and a length of 10 to $15 \mathrm{~mm}$, adjusted to each patient. The present study demonstrated that this procedure creates a larger-angle, taller, and wider neoaortic arch. We suggest that the use of GA-AP in the inner curvature of neoaorta is highly effective for enlarging the aortopulmonary space and preserving the aortic arch geometry in the Norwood procedure.

$\mathrm{Ou}$ and colleagues ${ }^{16}$ qualitatively classified aortic arch morphology after CoA repair as "Gothic," "Crenel," or "Romanesque" on magnetic resonance angiography. The angular (Gothic) aortic arch was associated with vascular abnormality and linked with a high risk of cardiovascular morbidity. The same could be applied to the aortic arch morphology after the Norwood procedure. Itatani and colleagues ${ }^{25}$ performed a computational hemodynamic analysis of the reconstructed aorta in 9 patients who underwent various types of aortic arch reconstruction in the Norwood procedure. They showed various types of neoaortic morphology and concluded that a smooth arch angle and large anastomotic space reduce aortic wall stress and energy loss, resulting in improved postoperative cardiac performance.

The aortopulmonary space and aortic arch angle after the Norwood procedure have rarely been studied, although they are very important anatomic features that would be related to postoperative morbidity. Furthermore, only a limited number of previous reports have examined the extrinsic compression of the bronchus and branch PA that results from the neoaorta, after the Norwood procedure. GarciaHernandez and colleagues ${ }^{26}$ reported that 2 patients who underwent aortic arch reconstruction, using autologous 
great vessel tissue only in the Norwood procedure, died from respiratory insufficiency owing to neoaortic compression of the branch PA and left main bronchus. Baker and colleagues ${ }^{27}$ reported ascending aortic extension to enlarge the aortopulmonary space in 3 patients with branch PA stenosis after the Norwood procedure. In addition, Menon and colleagues $^{28}$ reported posterior reduction aortoplasty for neoaortic compression of the left PA after the Norwood procedure.

In the present study, a total of 14 patients (38.9\%) experienced reintervention/reoperation for bronchomalacia or branch PA stenosis postoperatively. Balloon angioplasty, aortoplasty, aortopexy, PA patch plasty, and anterior translocation of the right PA were performed in the patients in this series. The univariate analysis showed that the significant risk factors associated with reintervention/reoperation for bronchomalacia or branch PA stenosis were the variables related to the narrowing of the aortopulmonary space, such as arch angle, arch width, and surgery without arch angle augmentation (NA group). Of these variables, the arch width was a significantly independent risk factor on the multivariate analysis. This result is consistent with recent reports that airway compression in patients with congenital heart diseases can be caused by a shortening of the interaortic distance between the ascending aorta and the dAo. ${ }^{29,30}$ Actually, bronchomalacia or branch PA stenosis after the Norwood procedure has occurred in some patients in whom the arch width was not sufficiently enlarged with GA-AP.

These results support the efficacy of arch angle augmentation with GA-AP for reducing the risk of those events by an adequate enlargement of the arch width. Although previous studies demonstrated that bilateral PA banding or a leftsided, right-ventricle-to-PA conduit is more likely to develop PA stenosis after the Norwood procedure, ${ }^{31,32}$ neither of them were risk factors associated with reintervention/reoperation for bronchomalacia, branch PA stenosis, or recoarctation in this series. In addition, we found that biventricular repair was 1 of the significant risk factors of bronchomalacia or branch PA stenosis after the Norwood procedure. Flow dynamics across the reconstructed arch can certainly affect growth of structures. In this study, no important gradients across the subaortic region were found after Yasui reconstruction $(3.5 \pm 3.3 \mathrm{~mm} \mathrm{Hg})$. Compared with singleventricle physiology, biventricular physiology and its corresponding cardiac morphology may be related to narrowing of the aortopulmonary space after the Norwood procedure.

Imaging approaches are important for full assessment of aortic arch morphology. Historically, catheter angiography has been performed, although admittedly, the nonplanar anatomy of a reconstructed aortic arch may preclude this approach, which has now been replaced in most centers by MDCTA and magnetic resonance angiography, with great advancement of these technologies. The main advantages of MDCTA are multiplanar reconstruction and 3-dimensional volume-rendered images. Scan times for MDCTA are much shorter than those for magnetic resonance angiography, and spatial resolution is higher. Although no standardized method has been established to evaluate the curvature of the aortic arch, centerline measurements have long been used in the analyses of aortic arch geometry. ${ }^{33,34}$ We modified the centerline measurement on the MDCTA for the present study. Further repeated studies of changes in aortic arch geometry after the Norwood procedure on MDCTA are needed.

However, limitations in the present study need to be acknowledged. This study is retrospective and nonrandomized, and from a single center, which impedes inference of possible causalities. In addition, biases could have been caused by patient selection and surgical judgment, especially as introduced by the 16 patients who were not evaluated because they died in the hospital before having postoperative MDCTA. Using only a small number of patients, with various diagnosis and surgical techniques, in a single center, limits the statistical power behind any conclusion. Because the Norwood procedures were performed by 1 of 2 surgeons, and the postoperative outcomes have improved over time, we cannot completely exclude potential bias of the era or surgeon, in drawing conclusions that favor the surgical technique of arch angle augmentation. In addition, the aortic arch geometric measurements in this study could be biased according to this methodology. Further clinical research and multicenter outcome studies on larger populations in a prospective design are needed to verify the results of the present study.

In conclusion, aortic arch reconstruction in the Norwood procedure causes the aortopulmonary space to narrow, resulting in postoperative recoarctation and neoaortic compression of the bronchus or the branch PA. Arch angle augmentation with GA-AP is effective for creating a sufficient aortopulmonary space with a smooth arch angle in the Norwood procedure, which can prevent adverse events postoperatively.

\section{Conflict of Interest Statement}

Authors have nothing to disclose with regard to commercial support.

\section{References}

1. Ohye RG, Sleeper LA, Mahony L, Newburger JW, Pearson GD, Lu M, et al Comparison of shunt types in the Norwood procedure for single-ventricle lesions. N Engl J Med. 2010;362:1980-92.

2. Norwood WI, Kirklin JK, Sanders SP. Hypoplastic left heart syndrome: experience with palliative surgery. Am J Cardiol. 1980;45:87-91.

3. Norwood WI, Lang P, Hansen DD. Physiologic repair of aortic atresiahypoplastic left heart syndrome. N Engl J Med. 1983;308:23-6.

4. Ashcraft TM, Jones K, Border WL, Eghtesady P, Pearl JM, Khoury PR, et al. Factors affecting long-term risk of aortic arch recoarctation after the Norwood procedure. Ann Thorac Surg. 2008;85:1397-401. 
5. Burkhart HM, Ashburn DA, Konstantinov IE, De Oliveira NC, Benson L, Williams WG, et al. Interdigitating arch reconstruction eliminates recurrent coarctation after the Norwood procedure. J Thorac Cardiovasc Surg. 2005;130:61-5.

6. Cleuziou J, Kasnar-Samprec J, Horer J, Eicken A, Lange R, Schreiber C. Recoarctation after the Norwood I procedure for hypoplastic left heart syndrome: incidence, risk factors, and treatment options. Ann Thorac Surg. 2013;95:935-40

7. Lamers LJ, Frommelt PC, Mussatto KA, Jaquiss RD, Mitchell ME, Tweddell JS. Coarctectomy combined with an interdigitating arch reconstruction results in a lower incidence of recurrent arch obstruction after the Norwood procedure than coarctectomy alone. J Thorac Cardiovasc Surg. 2012;143:1098-102.

8. Sakurai T, Rogers V, Stickley J, Khan N, Jones TJ, Barron DJ, et al. Single-center experience of arch reconstruction in the setting of Norwood operation. Ann Thorac Surg. 2012;94:1534-9.

9. Ishino K, Stumper O, De Giovanni JJ, Silove ED, Wright JG, Sethia B, et al. The modified Norwood procedure for hypoplastic left heart syndrome: early to intermediate results of 120 patients with particular reference to aortic arch repair. $J$ Thorac Cardiovasc Surg. 1999;117:920-30.

10. Poirier NC, Drummond-Webb JJ, Hisamochi K, Imamura M, Harrison AM, Mee RB. Modified Norwood procedure with a high-flow cardiopulmonary bypass strategy results in low mortality without late arch obstruction. $J$ Thorac Cardiovasc Surg. 2000;120:875-84.

11. Agnoletti G, Ou P, Celermajer DS, Boudjemline Y, Marini D, Bonnet D, et al. Acute angulation of the aortic arch predisposes a patient to ascending aortic dilatation and aortic regurgitation late after the arterial switch operation for transposition of the great arteries. J Thorac Cardiovasc Surg. 2008;135:568-72.

12. De CE, Trocchio G, Smeraldi A, Calevo MG, Pongiglione G. Aortic arch geometry and exercise-induced hypertension in aortic coarctation. Am J Cardiol. 2007; 99:1284-7.

13. Lashley D, Curtin J, Malcolm P, Clark A, Freeman L. Aortic arch morphology and late systemic hypertension following correction of coarctation of aorta. Congenit Heart Dis. 2007;2:410-5.

14. Ntsinjana HN, Biglino G, Capelli C, Tann O, Giardini A, Derrick G, et al. Aortic arch shape is not associated with hypertensive response to exercise in patients with repaired congenital heart diseases. J Cardiovasc Magn Reson. 2013;15:101.

15. Ou P, Celermajer DS, Raisky O, Jolivet O, Buyens F, Herment A, et al. Angular (Gothic) aortic arch leads to enhanced systolic wave reflection, central aortic stiffness, and increased left ventricular mass late after aortic coarctation repair: evaluation with magnetic resonance flow mapping. J Thorac Cardiovasc Surg. 2008;135:62-8.

16. Ou P, Celermajer DS, Mousseaux E, Giron A, Aggoun Y, Szezepanski I, et al. Vascular remodeling after "successful" repair of coarctation: impact of aortic arch geometry. J Am Coll Cardiol. 2007;49:883-90.

17. Fraser CD Jr, Mee RB. Modified Norwood procedure for hypoplastic left heart syndrome. Ann Thorac Surg. 1995;60(6 Suppl):S546-9.

18. Griselli M, McGuirk SP, Stumper O, Clarke AJ, Miller P, Dhillon R, et al. Influence of surgical strategies on outcome after the Norwood procedure. J Thorac Cardiovasc Surg. 2006;131:418-26.

19. McCrindle BW, Tchervenkov CI, Konstantinov IE, Williams WG, Neirotti RA, Jacobs ML, et al. Risk factors associated with mortality and interventions in 472 neonates with interrupted aortic arch: a Congenital Heart Surgeons Society study. J Thorac Cardiovasc Surg. 2005;129:343-50.
20. Hasegawa T, Oshima Y, Kadowaki T. Aortic arch augmentation using a pulmonary artery autograft patch and a reversed left subclavian artery flap for an interrupted aortic arch type B complex. Cardiol Young. 2014;24:559-62.

21. Mirsadraee S, Wilcox HE, Watterson KG, Kearney JN, Hunt J, Fisher J, et al. Biocompatibility of acellular human pericardium. J Surg Res. 2007;143: 407-14.

22. Duran CM, Gometza B, Kumar N, Gallo R, Bjornstad K. From aortic cusp extension to valve replacement with stentless pericardium. Ann Thorac Surg. 1995; 60(2 Suppl):S428-32.

23. Khaghani A, al-Kattan KM, Tadjkarimi S, Banner N, Yacoub M. Early experience with single lung transplantation for emphysema with simultaneous volume reduction of the contralateral lung. Eur J Cardiothorac Surg. 1997;11: 604-8.

24. Bernabei M, Margaryan R, Arcieri L, Bianchi G, Pak V, Murzi B. Aortic arch reconstruction in newborns with an autologous pericardial patch: contemporary results. Interact Cardiovasc Thorac Surg. 2013;16:282-5.

25. Itatani K, Miyaji K, Qian Y, Liu JL, Miyakoshi T, Murakami A, et al. Influence of surgical arch reconstruction methods on single ventricle workload in the Norwood procedure. J Thorac Cardiovasc Surg. 2012;144:130-8.

26. Garcia-Hernandez JA, Gonzalez-Rodriguez JD, Martinez-Lopez AI, CanalejoGonzalez D, Romero-Parreno A, de Soto JS, et al. Experience with the Norwood operation for hypoplastic left heart syndrome. Rev Esp Cardiol (Engl Ed). 2007; 60:732-8.

27. Baker CJ, Wells WJ, Derby CA, Rizi S, Starnes VA. Ascending aortic extension for enlargement of the aortopulmonary space in children with pulmonary artery stenosis. Ann Thorac Surg. 2005;80:1647-51.

28. Menon A, Jones T, Barron D, Stumper O, Brawn W. Posterior reduction aortoplasty for left pulmonary artery compression after Norwood procedure. Ann Thorac Surg. 2011;91:1300-1.

29. An HS, Choi EY, Kwon BS, Kim GB, Bae EJ, Noh CI, et al. Airway compression in children with congenital heart disease evaluated using computed tomography. Ann Thorac Surg. 2013;96:2192-7.

30. Kim YM, Yoo SJ, Kim WH, Kim TH, Joh JH, Kim SJ. Bronchial compression by posteriorly displaced ascending aorta in patients with congenital heart disease. Ann Thorac Surg. 2002;73:881-6.

31. Barron DJ, Brooks A, Stickley J, Woolley SM, Stumper O, Jones TJ, et al. The Norwood procedure using a right ventricle-pulmonary artery conduit: comparison of the right-sided versus left-sided conduit position. J Thorac Cardiovasc Surg. 2009;138:528-37.

32. Davies RR, Radtke WA, Klenk D, Pizarro C. Bilateral pulmonary arterial banding results in an increased need for subsequent pulmonary artery interventions. $J$ Thorac Cardiovasc Surg. 2014; 147:706-12.

33. Chiu P, Lee HP, Venkatesh SK, Ho P. Anatomical characteristics of the thoracic aortic arch in an Asian population. Asian Cardiovasc Thorac Ann. 2013;21:151-9.

34. Redheuil A, Yu WC, Mousseaux E, Harouni AA, Kachenoura N, Wu CO, et al. Age-related changes in aortic arch geometry: relationship with proximal aortic function and left ventricular mass and remodeling. J Am Coll Cardiol. 2011; 58:1262-70.

Key Words: aortic arch geometry, Norwood procedure, aortopulmonary space, arch angle augmentation 